\title{
Editorials
}

\section{Innovations in the utilization of health information technology in psychiatric services}

\author{
ROBERT M. PLOVNICK
}

\begin{abstract}
There is ever-increasing activity in applying information technology to various areas of healthcare, including mental health. Examples of innovations include applications in screening, treatment, clinical decision support, communication and coordination, telemedicine, Internet-based education and services, public health research, training and education, and bioinformatics. Issues and challenges include protection of privacy, managing narrative free text, assessing the reliability of information found online, and mitigating impact on clinical workflow. While many of the innovations described will not be fully realized until national information systems reach a larger scale, many are having a positive impact on mental healthcare today.

Declaration of Interest: None.
\end{abstract}

\section{INTRODUCTION}

Over the past several decades, information technology has revolutionized many industries, increasing efficiency and introducing previously unimagined capabilities. The full realization of information technology in healthcare has lagged for a variety of reasons, including the heterogeneity of health-related information and the complexity of systems in which healthcare is delivered. However, there is ever-increasing attention to practical applications and research in the area of health information technology worldwide, and this extends to mental health.

Applications of information technology in healthcare include electronic health records (EHRs), telemedicine, and Internet-based educational material targeting both patients and clinicians. Functions of health information systems include patient management, monitoring

Address for correspondence: Dr. R. Plovnick, Department of Quality Improvement and Psychiatric Services, American Psychiatric Association, 1000 Wilson Boulevard, Suite 1825, Arlington, Virginia 22209 (USA).

Fax: 01-703-907.7823

E-mail: rplovnick@psych.org resource utilization to inform policy management, administrative support, and public health research (Gulbinat et al., submitted for publication). There are several nation-level initiatives underway to expand or nationalize the use of information systems, and a component of these programs is expanded use of EHRs (Gulbinat et al., submitted for publication). There are various definitions of EHRs, but major supported functions include recording clinical and demographic data, viewing and managing results and imaging, order entry including electronic prescribing, and supporting clinical decisions (Desroches et al., 2008). Differences in funding sources, governance structure, mechanisms for communication and coordination, and a lack of technical standards for interoperability has led to wide variation in the progress of national initiatives (Arnold \& Wieners, 2008).

The early stage of national information system has not prevented innovations in the area of mental health information technology. Activities have touched on many aspects of care, including screening, treatment, and coordinating care of chronic illness. This article will provide a sampling of current activities as well as important challenges such as privacy protection and the handling of narrative information in the realm of mental health information technology. 


\section{APPLICATIONS AND INNOVATIONS}

\section{Screening and Assessment}

An active area in psychiatric clinical computing is the development of computer-administered questionnaires based on ratings scales and structured interviews that assign clinical diagnoses or measure symptom severity (Freedman, 2003). Computer-based screening systems have been implemented to reduce underdiagnosis in clinical settings, and to provide self-screening opportunities for individuals in the community. Remote Web-based screening and assessment exist for problem drinking (Cunningham et al., 2006), major depressive disorder, and anxiety disorders (Farvolden $e$ t al., 2003). An example of a clinical setting based screening is a major depressive disorder screening questionnaire completed by patients in a primary care waiting room, scanned into the EHR, and made available to the clinician at the time of the visit (Klein et al., 2006). EHRs facilitated tracking of depression screening rates in United States Department of Veterans Affairs primary care clinics, where the goal was to screen all patients annually (Kirkcaldy \& Tynes, 2006).

In addition to screening, Web-based questionnaires have been used to monitor response to treatment over time. For example, a system was designed to integrate with the EHR in the United Kingdom for monitoring neuropsychiatric symptoms, side effects, and quality of life for children treated for neurodevelopmental and neuropsychiatric disorders (Gringras et al., 2006).

\section{Clinical Decision Support}

Information systems facilitate clinical decision support, which is intended to inform decision making at the point of care. Examples are alerts triggered by newly available abnormal clinical information; critiques that draw a clinician's attention to an action recently taken (e.g. an order for a medication dosage that is well outside the typical range); and reminders for actions the clinician should consider taking (Denekamp, 2007). In an outpatient mental health clinic, computer reminders yielded higher rates of screening for mood disorder and complete documentation of DSM-IV criteria than did paper checklists (Cannon \& Allen, 2000). Computerized clinical decision support to assist in the actual diagnosis of psychiatric conditions, however, may be less effective. A study comparing a computerized and paper-based structured psychiatric diagnostic process (Bergman \& Fors, 2008) found a higher rate of correct diagnoses with the paper-based approach. In a study of physician responses to automated alerts, psychiatry was among the specialties most likely to override alerts without review (Long et al., 2008), which could suggest that reminders being delivered are not clinically pertinent, or that psychiatrists are less receptive to this type of intervention. The advantages and potential barriers to clinical decision support in psychiatry warrant further investigation.

\section{Treatment Settings}

Information technology can support treatment activities in both inpatient and outpatient settings. An account from a psychiatric hospital with a computerized information system reported several advantages that aided treatment: clinical information such as medication lists, laboratory results, and consultation reports were readily accessible by members of the treatment team; generation of documentation such as patient instructions, correspondence, and hospitalization summaries was efficient; and communication between attending psychiatrists and nonpsychiatric consultants was facilitated (Modai et al., 2002). For patients diagnosed with schizophrenia, medication documentation that directly impacts the course of treatment was found to be more complete and faster to retrieve in EHRs than in paper records at mental health centers (Tsai \& Bond, 2008). A study of the impact of EHRs on ambulatory care found an association between EHR use and avoiding benzodiazepine prescribing for patients with depression, although an association was not found for most of the remaining general health indicators studied (Linder et al., 2007).

\section{Improved Communication}

The management of individuals with chronic illness often involves clinicians in many settings and disciplines. Information technology can impact the management of chronic conditions such as depression and schizophrenia by identifying and flagging those patients with chronic illness for clinicians; making clinical information readily available to the team of clinicians that may be involved in an individual's care; engaging the patient by making clinical information and tailored education more readily available to him or her (Marchibroda, 2008); centralizing treatment planning; improving provider communication; providing lab value and medication alerts; and tracking patient outcomes (Young et al., 2007). A variety of information system features have been found to facilitate

Epidemiologia e Psichiatria Sociale, 18, 1, 2009 
treatment collaboration and positively impact outcome of chronic conditions including mental illness. These included the presence of an EHR system; populationbased reporting and feedback; and computerized prompts (Dorr et al., 2007). A software system developed to coordinate the care of patients with schizophrenia in the United States Department of Veterans Affairs, which included features such as clinical reminders and electronic messaging between members of the clinical team, led to measurable improvements in quality, such as changes in prescribing practices and an increase in the offering of family intervention (Young et al., 2004). The smart card, which is carried and controlled by the patient and can store information or the means to access information on the Internet, is another innovation used by the team of clinicians involved in an individual's care to share and update information at the point of care (Marschollek \& Demirbilek, 2006). Communication between clinicians at different organizations requires policy as well as technical coordination. Using psychiatric rehabilitation as a model, a study noted that organizational interventions such as aligning policies on sharing clinical information are required before information systems can connect healthcare organizations and government agencies involved in an individual's care (Timpka et al., 2007).

\section{Telepsychiatry}

Due to the prominence of verbal interaction and intervention, mental health is particularly suitable to telemedicine. This is particularly important given the multitude of populations that do not have access to psychiatric services due to geographical barriers or limited resources. Face-to-face interactions can be augmented by alternative modes of communication utilizing a variety of technologies, such as telephone, video conference, and web conference. Telepsychiatry services have been delivered in outpatient and emergency settings (Yellowlees et al., 2008); include therapy (Hilty et al., 2004), consultation service, education and training (Neufeld et al., 2007); and may prove important to an area affected by natural or manmade disaster (Yellowlees et al., 2008).

One of the applications of telemedicine is the collection and transmission of clinical measurements, such as blood glucose level by patients and families at home. This approach can also be used for behavioral information. A proposed platform would allow families to record and share digital camera video clips of behaviors related to autism (Oberleitner et al., 2004). Also, passive infrared sensors were used in the homes of elderly people to mon- itor number of outings and sleep patterns to detect dementia (Suzuki et al., 2007). New types of behavioral information that is often unobservable in the clinical setting could be collected and transmitted from home, and, coupled with EHRs, shared among clinicians.

\section{E-Mental Health}

E-mental health refers to services and information provided through the Internet (Cleary et al., 2008). Individuals, particularly those with chronic illness such as depression, are increasingly turning to the Internet for health information (Bundorf et al., 2006). As access to the Internet increases, so does the search for health information online: $75-80 \%$ of American Internet users have searched for health information online, and $75 \%$ of those with a chronic condition reported that their searches affected a decision about treatment (Fox, 2008). Examples of Internet-based psychoeducation abound in the literature, ranging from information targeting adolescent suicide survivors (Hoffmann, 2006) to material on depressive symptoms in persons living with HIV/AIDS (Lai et al., 2008).

In addition to serving as a resource for information, the Internet provides opportunities for new forms of interaction and communication. Technologies such as online message boards and chat rooms support virtual communities for communication and the exchange of ideas among healthcare providers, patients, family members, and members of the general public. Virtual communities may support interaction among clinicians for healthcare delivery and research teams, between clinicians and patients for disease management, and between patients that share a diagnosis such as depression (Demiris, 2006).

The Internet has also been used for the delivery of therapy, with and without clinician support. Internetbased cognitive behavior therapy interventions have been described for a range of conditions, including post traumatic stress disorder, panic disorder, and depression (Emmelkamp, 2005). Internet-facilitated therapy may be delivered by a wider range of clinicians, and therefore reach a larger patient population. For example, an Internet based therapy program for panic disorder was found to be effective when paired with support by either psychologists or general medical practitioners (Shandley et al., 2008). Internet-based interventions may also reach individuals who may otherwise not seek help, illustrated by a highly used Internet-based intervention targeting heavy drinking (Linke et al., 2007). 
The expansion of interactive, graphics-rich, threedimensional, Internet-based virtual worlds has led to novel healthcare applications. Virtual worlds have been used to simulate the auditory and visual hallucinations of patients with schizophrenia, affording a new format of education for clinicians and patients' families alike (Yellowlees \& Cook, 2006). Utilizing virtual worlds for the delivery of psychotherapy is also under active exploration (Gorini et al., 2008).

\section{Public Health Research}

By decreasing the burden for data collection and presenting information in a more structured form, information systems facilitate population level research and analysis. An EHR network covering over 2 million patients was recently employed to assess the rate of antidepressant medication use in persons with a diagnosis of depression and medical comorbidities (Gill et al., 2008). Collection of data for this study was facilitated by capturing diagnoses and medications from structured fields in the electronic record rather than from manual review of entire paper records. Information from an EHR system was used to monitor adherence to medication management guidelines in patients with schizophrenia, with the electronic method of data collection allowing for a significantly larger study population than a manual review of written records would allow (Owen et al., 2004). Registries, databases of cases of a given condition, have also been successfully implemented for research and management of depression (Kilbourne et al., 2006). As is the case for exchanging information for patient care, research studies that involve multiple organizations require policy and technical solutions to collect information from incompatible information systems (Winter et al., 2007).

\section{Education}

Health information technology and the Internet have been used to expand education and support not only for the general public, but also for mental health professionals. A suicide prevention resource targeting rural Australia provides online educational material and the opportunity for online interaction at three levels: the general public, members of the community who may deal with individuals at risk, and professional health workers (Penn et al., 2005). With advantages such as constant availability and portability across institutions and settings, Internet-based learning modules are increasingly popular as tools to augment psychiatric education (Chan \& Robbins, 2006). The use of EHRs as tools in the education of mental health professionals in training has only begun to be explored (Keenan et al., 2006).

\section{Bioinformatics}

Advances in the field of genomics are bringing new insights to the field of psychiatry. Bioinformatics, which focuses on managing and analyzing large amounts of data, is particularly pertinent in the study of psychiatric disorders, which like other complex genetic traits may involve hundreds of genes (Kelsoe, 2004). A national database of biological materials and environmental information associated with neurological and psychiatric diseases in Hungary is an example of emerging resources (Molnar \& Bencsik, 2006). As information about the genetic underpinning of psychiatric illness expands and influence treatment decisions, informatics solutions will be needed to guide medication selection (Preskorn, 2006).

\section{ISSUES}

\section{Confidentiality, Privacy, and Security}

The ability of health information systems to make records more accessible for treatment purposes also increases the risk of unauthorized access. Medical records may contain sensitive information including financial information, mental health, sexually transmitted diseases, and reproductive history. A major source of protection of records to date has been the storage of information in fragmented and difficult to locate paper-based records (Rothstein \& Talbott, 2006). There are numerous examples of devices such as portable flash drives, laptops, or compact disks containing patient records being misplaced or stolen, and patient information has been inadvertently posted on the Web (Wernick, 2006). Medical professionals have accessed the records of celebrities for whose care they were not involved (Ornstein, 2008). An emerging source of breach is the posting by medical professionals of identifiable information and images on medical weblogs (Lagu et al., 2008). Limiting access to health information is an ongoing challenge.

Individuals may withhold health information from clinicians if confidentiality, privacy, and security are not assured. A recent poll found that one in six patients withheld information from health professionals because of worries it might be disclosed (HarrisInteractive, 2007). 
This is likely to persist if breaches continue, hampering the clinician's ability to gather critical information and form a therapeutic relationship. In one study individuals identified a range of information from their records they would not want shared on a national database, including depression, erectile dysfunction, and asthma (Powell et al., 2006). Challenges in establishing an approach to protection include respecting individuals' wishes for how their information is shared; accounting for the variation in information that patients will categorize as sensitive; maintaining protection as information is shared between systems and settings; and ensuring that access to key information by clinicians at the point of care is not overly cumbersome.

Many approaches have been proposed and implemented to protect sensitive health information, often incorporating both technological solutions and organizational policy. Key elements include the ability to track access and modification to records; giving the patient a degree of control over who can access their information, typically with an override policy for urgent situations (Mandl et al., 2001); limiting information access to clinicians with a direct therapeutic relationship (Lovis et al., 2007); and encryption (Meingast et al., 2006). Several national information systems are implementing masking capabilities, where individuals can limit access or transfer of their own sensitive information (Pritts \& Connor, 2007). Key to achieving acceptable protection will be the acknowledgement of its importance and incorporation early in the development cycle of information systems.

\section{Narrative Free Text}

Clinical documentation in psychiatry includes a great deal of narrative free text, which is less computer-readable than structured, codified information. Information contained in narrative notes is less amendable to extraction, aggregation, and analysis than more structured information in electronic records, although a study quantifying patient non-adherence using the text of physician notes (Turchin et al., 2007) illustrates that this type of analysis is possible. The availability of "copy-and-paste" yields sections of notes, including the mental status exam (Thielke et al., 2007), that may be redundant, perpetuate outdated or incorrect information, and lose meaning when language is repeated over time (Hirschtick, 2006). Informal reminders, observations, and diagrams written in the margins of paper records to serve as memory aids do not have a clear counterpart in the template-based structure of EHRs (Frey, 2007).

\section{Reliability of Online Information}

A review of websites pertaining to psychological trauma illustrates that while health information on the Internet is abundant, it is often inaccurate or unreliable, and in some instances, potentially harmful (Bremner et al., 2006). A review of online information on alcohol, tobacco, and other drugs also noted the wide range of the quality of available information (Monahan \& Colthurst, 2001). There will be an increasing role for mental health professionals to help individuals find reliable information and to interpret information found online.

\section{Impact on Clinical Workflow}

The use of a computer during the clinical encounter may inhibit communication by drawing the clinician's attention to the screen, and by influencing the organization of the visit (Frankel et al., 2005). Therefore, attention must be paid to the physical configuration of the clinical setting to optimize verbal and nonverbal communication (McGrath et al., 2007). An EHR malfunction during an outpatient psychiatric encounter can be particularly problematic as it can lead to lost narrative information and interrupt the flow of the patient-psychiatrist interaction (Kaufman \& Hyler, 2005). Information overload and difficulty in identifying the most pertinent clinical and scientific information threaten to erode the limited time available to clinicians (Fava \& Guidi, 2007; Weiner \& Biondich, 2006). Patient satisfaction, particularly in the psychiatric patient population where the patient-clinician relationship is vital, needs to be monitored as electronic charting is introduced into the clinical encounter (Stewart et al., 2005). Training of clinicians in basic computer skills such as information retrieval may be required to optimize use of technology for clinical and educational purposes (Lim et al., 2006).

The introduction of health information technology can lead to unintended consequences. Several categories of unintended consequences have been reported with the introduction of computerized provider order entry (CPOE), including increased workload for clinicians and generation of new kinds of errors (Campbell et al., 2006). The introduction of CPOE into a pediatric hospital led to a measurable increase in mortality rate (Han et al., 2005). To minimize unintended consequences, information technology innovations must be implemented thoughtfully with close involvement of the clinicians and patients affected. 


\section{CONCLUSION}

This overview was intended to provide illustrations of the range of activity in the area of heath information technology applied to mental health. Health information technology has the potential to augment screening and treatment, improve communication in fragmented treatment situations, expand the reach of limited resources, provide new opportunities for public health research, and overcome barriers of geography in disseminating information and services. Challenges include protecting sensitive information, handling narrative text, filtering information of varying quality retrieved online, and addressing impacts on clinical interaction. Research and development in the areas covered is likely to continue in the years ahead, and new innovations will emerge as technology advances. While many of the innovations described will not be fully realized until national information systems reach a larger scale, many are having a positive impact on mental healthcare today.

\section{REFERENCES}

Arnold S.L. \& Wieners W.W. (2008). Electronic health records: a global perspective. Healthcare Information and Management Systems Society. Retrieved December 1, 2008, from http://www.himss.org/content/files/200808_EHRGlobalPerspective_whitepaper.pdf.

Bergman L.G. \& Fors U.G. (2008). Decision support in psychiatry - a comparison between the diagnostic outcomes using a computerized decision support system versus manual diagnosis. BMC Medical Informatics and Decision Making 8, 9.

Bremner J.D., Quinn J., Quinn W. \& Veledar E. (2006). Surfing the net for medical information about psychological trauma: an empirical study of the quality and accuracy of trauma-related websites. Medical Informatics and the Internet in Medicine 31, 227-236.

Bundorf M.K., Wagner T.H., Singer S.J. \& Baker L.C. (2006). Who searches the internet for health information? Health Services Research $41,819-836$.

Campbell E.M., Sittig D.F., Ash J.S., Guappone K.P. \& Dykstra R.H. (2006). Types of unintended consequences related to computerized provider order entry. Journal of the American Medical Informatics Association 13, 547-556.

Cannon D.S. \& Allen S.N. (2000). A comparison of the effects of computer and manual reminders on compliance with a mental health clinical practice guideline. Journal of the American Medical Informatics Association 7, 196-203.

Chan C.H. \& Robbins L.I. (2006). E-Learning systems: promises and pitfalls. Academic Psychiatry 30, 491-497.

Cleary M., Walter G. \& Matheson S. (2008). What is the role of e-technology in mental health services and psychiatric research? Journal of Psychosocial Nursing and Mental Health Services 46, 42-48.

Cunningham J.A., Humphreys K., Kypri K. \& Van Mierlo T. (2006). Formative evaluation and three-month follow-up of an online personalized assessment feedback intervention for problem drinkers. Journal of Medical Internet Research 8, e 5.

Demiris G. (2006). The diffusion of virtual communities in health care: concepts and challenges. Patient Education and Counseling 62, 178-188.
Denekamp Y. (2007). Clinical decision support systems for addressing information needs of physicians. Israel Medical Association Journal 9, 771-776.

Desroches C.M., Campbell E.G., Rao S.R., Donelan K., Ferris T.G., Jha A., Kaushal R., Levy D.E., Rosenbaum S., Shields A.E. \& Blumenthal D. (2008). Electronic health records in ambulatory care: A national survey of physicians. New England Journal of Medicine 359, 50-60.

Dorr D., Bonner L.M., Cohen A.N., Shoai R.S., Perrin R., Chaney E. \& Young A.S. (2007). Informatics systems to promote improved care for chronic illness: a literature review. Journal of the American Medical Informatics Association 14, 156-163.

Emmelkamp P.M. (2005). Technological innovations in clinical assessment and psychotherapy. Psychotherapy and Psychosomatics 74, 336-343.

Farvolden P., Mcbride C., Bagby R.M. \& Ravitz P. (2003). A Webbased screening instrument for depression and anxiety disorders in primary care. Journal of Medical Internet Research 5, e 23.

Fava G.A. \& Guidi J. (2007). Information overload, the patient and the clinician. Psychotherapy and Psychosomatics 76, 1-3.

Fox S. (2008). The engaged e-patient population. Pew Internet \& American Life Project. Retrieved December 1, 2008, from, http://www.pewinternet.org/pdfs/PIP_Health_Aug08.pdf.

Frankel R., Altschuler A., George S., Kinsman J., Jimison H., Robertson N.R. \& Hsu J. (2005). Effects of exam-room computing on clinician-patient communication: a longitudinal qualitative study. Journal of General Internal Medicine 20, 677-682.

Freedman J. (2003). The role of information technology in evidenced-based practice. Psychiatric Clinics of North America 26, 833850 , vii-viii.

Frey J.J., 3rd (2007). A piece of my mind. At a loss for words. Journal of the American Medical Association 297, 1751-1752.

Gill J.M., Chen Y.X. \& Lieberman M.I. (2008). Management of depression in ambulatory care for patients with medical co-morbidities: a study from a national Electronic Health Record (EHR) network. International Journal of Psychiatry in Medicine 38, 203-215.

Gorini A., Gaggioli A., Vigna C. \& Riva G. (2008). A second life for eHealth: prospects for the use of 3-D virtual worlds in clinical psychology. Journal of Medical Internet Research 10, e 21.

Gringras P., Santosh P. \& Baird G. (2006). Development of an Internet-based real-time system for monitoring pharmacological interventions in children with neurodevelopmental and neuropsychiatric disorders. Child: Care, Health and Development 32, 591-600.

Gulbinat W., Amaddeo F., Ito H., Medina-Mora E., Mubbashar M., Ndetei D. \& Plovnick R. (submitted for publication). Statistics and Information Systems.

Han Y.Y., Carcillo J.A., Venkataraman S.T., Clark R.S., Watson R.S., Nguyen T.C., Bayir H. \& Orr R.A. (2005). Unexpected increased mortality after implementation of a commercially sold computerized physician order entry system. Pediatrics 116, 1506-1512.

Harrisinteractive (2007). Many U.S. adults are satisfied with use of their personal health information. Harris Poll \#27. Retrieved December 1, 2008, from, http://www.harrisinteractive.com/harris_poll/index.asp? $\mathrm{PID}=743$.

Hilty D.M., Marks S.L., Urness D., Yellowlees P.M. \& Nesbitt T.S. (2004). Clinical and educational telepsychiatry applications: a review. Canadian Journal of Psychiatry 49, 12-23.

Hirschtick R.E. (2006). A piece of my mind. Copy-and-paste. Journal of the American Medical Association 295, 2335-2336.

Hoffmann W.A. (2006). Telematic technologies in mental health caring: a web-based psychoeducational program for adolescent suicide survivors. Issues in Mental Health Nursing 27, 461-474.

Kaufman K.R. \& Hyler S.E. (2005). Problems with the electronic medical record in clinical psychiatry: a hidden cost. Journal of Psychiatric Practice 11, 200-204.

Keenan C.R., Nguyen H.H. \& Srinivasan M. (2006). Electronic medical records and their impact on resident and medical student education. Academic Psychiatry 30, 522-527.

Kelsoe J.R. (2004). Genomics and the Human Genome Project: implications for psychiatry. International Review of Psychiatry 16, 294-300. 
Kilbourne A.M., Mcginnis G.F., Belnap B.H., Klinkman M. \& Thomas M. (2006). The role of clinical information technology in depression care management. Administration and Policy in Mental Health 33, 54-64.

Kirkcaldy R.D. \& Tynes L.L. (2006). Depression screening in a VA primary care clinic. Psychiatric Services 57, 1694-1696.

Klein E.W., Hunt J.S. \& Leblanc B.H. (2006). Depression screening interfaced with an electronic health record: a feasibility study in a primary care clinic using optical mark reader technology. Primary Care Companion to the Journal of Clinical Psychiatry 8, 324-328.

Lagu T., Kaufman E.J., Asch D.A. \& Armstrong K. (2008). Content of weblogs written by health professionals. Journal of General Internal Medicine 23, 1642-1646.

Lai T.Y., Larson E.L., Rockoff M.L. \& Bakken S. (2008). User acceptance of HIV TIDES-Tailored Interventions for Management of Depressive Symptoms in persons living with HIV/AIDS. Journal of the American Medical Informatics Association 15, 217-226.

Lim R.F., Hsiung B.C. \& Hales D.J. (2006). Lifelong learning: skills and online resources. Academic Psychiatry 30, 540-547.

Linder J.A., Ma J., Bates D.W., Middleton B. \& Stafford R.S. (2007). Electronic health record use and the quality of ambulatory care in the United States. Archives of Internal Medicine 167, 1400-1405.

Linke S., Murray E., Butler C. \& Wallace P. (2007). Internet-based interactive health intervention for the promotion of sensible drinking: patterns of use and potential impact on members of the general public. Journal of Medical Internet Research 9, e 10.

Long A.J., Chang P., Li Y.C. \& Chiu W.T. (2008). The use of a CPOE $\log$ for the analysis of physicians' behavior when responding to drug-duplication reminders. International Journal of Medical Informatics 77, 499-506.

Lovis C., Spahni S., Cassoni N. \& Geissbuhler A. (2007). Comprehensive management of the access to the electronic patient record: towards trans-institutional networks. International Journal of Medical Informatics 76, 466-470.

Mandl K.D., Szolovits P. \& Kohane I.S. (2001). Public standards and patients' control: how to keep electronic medical records accessible but private. British Medical Journal 322, 283-287.

Marchibroda J.M. (2008). The impact of health information technology on collaborative chronic care management. Journal of Managed Care Pharmacy 14, S3-11.

Marschollek M. \& Demirbilek E. (2006). Providing longitudinal health care information with the new German Health Card: A pilot system to track patient pathways. Computer Methods and Programs in Biomedicine 81, 266-271.

Mcgrath J.M., Arar N.H. \& Pugh J.A. (2007). The influence of electronic medical record usage on nonverbal communication in the medical interview. Health Informatics Journal 13, 105-118.

Meingast M., Roosta T. \& Sastry S. (2006). Security and privacy issues with health care information technology. Conference Proceedings: Annual International Conference of the IEEE Engineering in Medicine and Biology Society 1, 5453-5458.

Modai I., Ritsner M., Silver H. \& Kurs R. (2002). A computerized patient information system in a psychiatric hospital. Psychiatric Services 53, 476-478.

Molnar M.J. \& Bencsik P. (2006). Establishing a neurological-psychiatric biobank: banking, informatics, ethics. Cellular Immunology 244, 101-104.

Monahan G. \& Colthurst T. (2001). Internet-based information on alcohol, tobacco, and other drugs: issues of ethics, quality, and accountability. Substance Use and Misuse 36, 2171-2180.

Neufeld J.D., Yellowlees P.M., Hilty D.M., Cobb H. \& Bourgeois J.A. (2007). The e-Mental Health Consultation Service: providing enhanced primary-care mental health services through telemedicine. Psychosomatics 48, 135-141.

Oberleitner R., Laxminarayan S., Suri J., Harrington J. \& Bradstreet J. (2004). The potential of a store and forward tele-behavioral platform for effective treatment and research of autism. Conference Proceedings: Annual International Conference of the IEEE Engineering in Medicine and Biology Society 5, 3294-3296.
Ornstein C. (2008). UCLA workers snooped in Spears' medical records. Los Angeles Times. 15 March 2008.

Owen R.R., Thrush C.R., Cannon D., Sloan K.L., Curran G., Hudson T., Austen M. \& Ritchie M. (2004). Use of electronic medical record data for quality improvement in schizophrenia treatment. Journal of the American Medical Informatics Association 11, 351-357.

Penn D.L., Simpson L., Edie G., Leggett S., Wood L., Hawgood J., Krysinska K., Yellowlees P. \& De Leo D. (2005). Development of ACROSSnet: an online support system for rural and remote community suicide prevention workers in Queensland, Australia. Health Informatics Journal 11, 275-293.

Powell J., Fitton R. \& Fitton C. (2006). Sharing electronic health records: the patient view. Informatics in Primary Care 14, 55-57.

Preskorn S.H. (2006). Pharmacogenomics, informatics, and individual drug therapy in psychiatry: past, present and future. Journal of Psychopharmacology 20, 85-94.

Pritts J. \& Connor K. (2007). The implementation of e-consent mechanims in three countries: Canada, England, and the Netherlands. United States Department of Health and Human Services. Retrieved December 1, 2008, from, http://ihcrp.georgetown.edu/pdfs/prittse-consent.pdf.

Rothstein M.A. \& Talbott M.K. (2006). Compelled disclosure of health information: protecting against the greatest potential threat to privacy. Journal of the American Medical Association 295, 2882-2885.

Shandley K., Austin D.W., Klein B., Pier C., Schattner P., Pierce D. \& Wade V. (2008). Therapist-assisted, Internet-based treatment for panic disorder: can general practitioners achieve comparable patient outcomes to psychologists? Journal of Medical Internet Research 10, e 14.

Stewart R.F., Buchanan H.S., Bailey B., Schuyler M. \& Kroth P.J. (2005). Effect of electronic charting on the patient-psychiatrist relationship. AMIA Annual Symposium Proceedings, 1122.

Suzuki T., Murase S., Tanaka T. \& Okazawa T. (2007). New approach for the early detection of dementia by recording in-house activities. Telemedicine Journal and E-Health 13, 41-44.

Thielke S., Hammond K. \& Helbig S. (2007). Copying and pasting of examinations within the electronic medical record. International Journal of Medical Informatics 76, Suppl 1, S122-128.

Timpka T., Bang M., Delbanco T. \& Walker J. (2007). Information infrastructure for inter-organizational mental health services: an actor network theory analysis of psychiatric rehabilitation. Journal of Biomedical Informatics 40, 429-437.

Tsai J. \& Bond G. (2008). A comparison of electronic records to paper records in mental health centers. International Journal for Quality in Health Care 20, 136-143.

Turchin A., Kolatkar N.S., Pendergrass M.L. \& Kohane I.S. (2007). Computational analysis of non-adherence and non-attendance using the text of narrative physician notes in the electronic medical record. Medical Informatics and the Internet in Medicine 32, 93-102.

Weiner M. \& Biondich P. (2006). The influence of information technology on patient-physician relationships. Journal of General Internal Medicine 21 Suppl 1, S35-39.

Wernick A.S. (2006). Data theft and state law. Journal of AHIMA 77, 40-44; quiz 47-48.

Winter A., Funkat G., Haeber A., Mauz-Koerholz C., Pommerening K., Smers S. \& Stausberg J. (2007). Integrated information systems for translational medicine. Methods of Information in Medicine 46, 601-607.

Yellowlees P.M. \& Cook J.N. (2006). Education about hallucinations using an internet virtual reality system: a qualitative survey. Academic Psychiatry 30, 534-539.

Yellowlees P., Burke M.M., Marks S.L., Hilty D.M. \& Shore J.H. (2008). Emergency telepsychiatry. Journal of Telemedicine and Telecare 14, 277-281.

Young A.S., Mintz J., Cohen A.N. \& Chinman M.J. (2004). A network-based system to improve care for schizophrenia: the Medical Informatics Network Tool (MINT). Journal of the American Medical Informatics Association 11, 358-367.

Young A.S., Chaney E., Shoai R., Bonner L., Cohen A.N., Doebbeling B., Dorr D., Goldstein M.K., Kerr E., Nichol P. \& Perrin R. (2007). Information technology to support improved care for chronic illness. Journal of General Internal Medicine 22, Suppl 3, 425-430. 